\title{
Ortaokul Öğrencilerinin Ters Yüz Öğrenme Hazırbulunuşlukları ile Araştırma/Sorgulamaya Yönelik Tutumları Arasındaki iliş̦i
}

\author{
İshak KOZiKOĞLU* \\ Kader CAMUȘCU
}

Öz: Bu araştırmanın amacı, ortaokul öğrencilerinin ters yüz öğrenme hazırbulunuşlukları ile araştırma/sorgulamaya yönelik tutumları arasındaki ilişkiyi belirlemektir. İlişkisel tarama modelinde desenlenen bu araştırma, Van ilinde öğrenim gören 362 ortaokul öğrencisi ile gerçekleştirilmiştir. Veri toplama araçları olarak "Ortaokul Öğrencileri için Ters Yüz Öğrenme Hazırbulunuşluk Ölçeği” ve "Ortaokul Öğrencileri için Araştırma/Sorgulamaya Dönük Tutum Ölçeği” kullanılmıştır. Verilerin analizinde betimsel istatistikler, fark analizleri ve Pearson Çarpım Momentler Korelasyon Katsayısı kullanılmıştır. Araştırmanın sonucunda, ortaokul öğrencilerinin ters yüz öğrenme hazırbulunuşluklarının ve araştırma sorgulamaya yönelik tutumlarının yüksek düzeyde olduğu belirlenmiştir. Araştırmada, evinde internet bağlantısı olan ve yüksek sosyo-ekonomik gelişmişlik düzeyine sahip okullarda öğrenim gören öğrencilerin ters yüz öğrenme hazırbulunuşluklarının ve araştırma sorgulamaya yönelik tutumlarının daha yüksek olduğu saptanmıştır. Ayrıca, ortaokul öğrencilerinin araştırma sorgulamaya yönelik tutumları ile ters yüz öğrenme hazırbulunuşlukları arasında orta düzeyde, pozitif ve anlamlı bir ilişkinin olduğu sonucuna ulaşılmıştır.

Anahtar Sözcükler: Ters Yüz Edilmiş Öğrenme, Araştırma, Sorgulama, Tutum, Ortaokul Öğrencileri

\section{Relationship Between Secondary School Students' Flipped Learning Readiness and Attitudes Towards Researching/Questioning}

\begin{abstract}
The aim of this study is to determine the relationship between secondary school students' flipped learning readiness and their attitudes towards researching/questioning. This study using correlational survey model was carried out with 362 secondary school students studying in Van. As data collection tools, "Flipped Learning Readiness Scale for Secondary School Students and "Attitude towards Researching/Questioning Scale for Secondary School Students" were used. In data analysis; descriptive statistics, differential analysis and Pearson Product Moment Correlation Coefficient were used. As a result, it was revealed that secondary school students' attitudes towards researching/questioning and their flipped learning readiness are at high level. This study concluded that students, who study at schools with high socio-economic development level and with internet connection at home had higher level of flipped learning readiness and attitudes towards researching/questioning. In addition, a positive and significant relationship was found between secondary school students' attitudes towards researching/questioning and their flipped learning readiness.
\end{abstract}

Keywords: Flipped Learning, Researching, Questioning, Attitude, Secondary School Students 
Bilim ve teknolojinin hızla gelişmesiyle, sosyal yapıdaki değişim ve gelişim kaçınılmaz olmuştur. Bu değişim ve gelişimler eğitim alanında da kendini göstermek durumunda kalmıştır. Günümüz çağında örgün ya da yüz yüze öğrenme bireylerin eğitim ihtiyaçlarını karşılamakta tek başına yeterli olmamakta ve bu durum öğrenmeyi okul ortamının dışına taşımaktadır. Dolayısıyla, eğitimciler eğitim teknolojilerinden de faydalanarak yeni arayışlara yönelmektedirler.

Bilgisayarlar okulda öğrencilerin ara sıra kullanacakları bir yerle sınırlandırılırsa öğrencilerin öğrenme potansiyellerindeki etkisi düşmektedir. Fakat bilgisayarlar eğitime entegre edilir ve gerçek yaşam problemlerine uygulanırsa öğrenciler, öğrenmede bilgisayarları doğal araçlar olarak kullanma yeteneğini kazanmaktadırlar (Davis ve Shade, 1994). Teknolojinin gelişmesi, teknolojinin eğitim kurumlarının her alanına entegre olmasını mecburi kılmıştır. Modern eğitim anlayışında öğrenen bireyin merkeze alındı̆̆ı ve gelişen teknoloji imkânlarının öğrencilere bilgiye pek çok kaynaktan ulaşma imkânı sağladığı açıktır. Bu gelişmelere bağlı olarak eğitim sistemimiz "davranış̧̧" yaklaşımdan "yapılandırmacılık" anlayışına doğru yol almıştır (Kertil, 2008). Geleneksel eğitim anlayışında öğretmen bilginin tek kaynağı olarak görülmekte ve buna bağlı olarak bilgiler öğretmenden öğrenciye aktarılmaktadır. Bu durum günümüz ihtiyacını karşılamada ve kalıcı öğrenmeler sağlamada yetersiz kalmaktadır. Öte yandan yapılandırmacı yaklaşımda öğrenciler pasif olmayıp, aktif olarak öğrenme sürecine katılır ve öğretmen ise bilgiyi aktaran değil rehber rolündedir. Bu anlayışla birlikte, öğrenme sınıf dışına çıkarak eğitimde alternatif modeller ortaya çıkmıştır. Bu değişim ve gelişmelerle birlikte son yıllarda "ters yüz öğrenme modeli" karşımıza çıkmaktadır.

Öğrencilere bireysel öğrenmelerinde karşılaştıkları problemlere odaklanma fırsatı sunan ters yüz öğrenme, evde yapılanlar ile sınıf içi öğrenmelerin yer değiştirmesi olarak tanımlanmaktadır (Bishop ve Verleger, 2013). Türkçe alanyazında ters yüz edilmiş öğrenme, "evde ders, okulda ödev modeli" (Demiralay ve Karataş, 2014); "dönüştürülmüş sınıf" (Akkoyunlu ve Gündüz, 2015); "çevrilmiş öğrenme modeli" (Sever, 2014); "ters yüz sınıf sistemi" (Gençer, Gürbulak ve Adıgüzel, 2014) gibi farklı tanımlamalarla karşımıza çıkmaktadır. Yurtdışı alanyazında "flipped learning" kavramıyla bilinen modelin, sınıf içi ve sınıf dışı öğrenmeleri tersine çevirmesi yönüyle bu çalışmada "ters yüz öğrenme" olarak isimlendirilmesi tercih edilmiştir.

Ters yüz öğrenme modeli, Miami Üniversitesindeki (Ohio) bir grup ekonomi profesörleri tarafından kullanım tekniklerini göstermek amacıyla ortaya çıkmıştır (Lage, Platt ve Treglia, 2000). 2007 yılında ise Jonathan, Bergman ve Aaron Same'in dersi kaçıran öğrenciler için canlı dersleri kayıt altına alıp çevrimiçi yayınlamaları ile geçerlik kazanmıştır. Ayrıca, Northern Colorada Üniversitesi'nde görev yapan öğretim üyelerinin indirilebilir videolar kullanmaya başlamasıyla (Bergman ve Sams, 2012) 3000'in üzerinde katılımcıya ulaşarak birkaç ayda popüler olmaya başlamıştır (Talbert, 2012). Bu uygulamalar zamanla daha sistematik hale getirilerek ters yüz öğrenme modelinin eğitimde alternatif bir model olarak yaygınlaşmasına zemin hazırlamıştır. Her bireyin farklı bir öğrenme yeteneğine sahip olduğunu tanıması, bireyi öğrenme sürecine aktif olarak katması ve bireysel öğrenmesini sağlama düşüncesi modern eğitim anlayışının özelliklerindendir. Geleneksel eğitimin aksine, ters yüz öğrenme modeli teorik bilgiyi evde öğrencinin öğrenip, öğrendiklerini ise sınıfta uygulamaya dökmesini sağlayan bir uygulamadır (Zownorega, 2013). Ters yüz sınıf modelinde, genellikle öğretmen ders içeriğini önceden videoya çekmekte ve öğrencilerin ders dışı bu içeriğe ulaşması sağlanmaktadır. Öğrenci videoyu izlerken kendi öğrenme hızına göre ayarlayabilir, videoyu tekrar tekrar izleyebilir ve anlamadığı yerlere tekrar dönebilir ya da çok iyi bildiği bir konu ise ilerletebilir (Johnson, 2012). Bu durum, hem öğrencinin kuramsal bilgiyi sınıf dışında öğrenmesini hem de bireysel öğrenme hızına göre ilerlemesini sağlamaktadır.

Ters yüz öğrenme modeli, mevcut eğitim uygulamalarına farklı bir bakış açısı kazandırdığı ve öğrenmeyi sınıf dışına taşıdığı için öğretme-öğrenme süreçlerine çeşitli avantajlar sunmaktadır. Avantajlarından biri, geleneksel modele göre kişiler arası etkileşimi artırmaktadır (Johnson, 2012). Ters yüz öğrenmede öğrenci, kuramsal bilgiyi öğretmenin paylaştığı materyallerle (video, ders notları vb.) sınıf dışında öğrenmektedir. Geleneksel modelde ders anlatmak için ayrılan süre, ters yüz öğrenmede tartışma, soru cevap, proje, deney ve beyin fırtınası gibi sınıf içi etkinliklerine ayrılmaktadır. Böylece öğrenci-öğrenci ve öğrenci-öğretmen etkileşimi daha fazla olmakta ve ders saatleri uygulamalı etkinliklere ayrılarak daha etkili kullanılmaktadır. 
Öğrenciler bireysel hızlarına göre ilerledikleri için bireysel farklılıklara bağlı oluşan engeller ortadan kalkmaktadır. Öğretmenlerin öğrencilere 7/24 ulaşma imkânı olmakta ve böylece konu yetiştirememe gibi bir sorun ortadan kalkmaktadır. Bu durumda, ters yüz öğrenme modeli okul dışında teknolojinin kullanılmasıyla sınıftaki öğrenmeleri kolaylaştırmakta ve sınıftaki öğretmen-öğrenci etkileşiminin artmasını sağlamaktadır (Kozikoğlu, 2019). Her ne kadar teknolojik altyapı yetersizliği, öğretmen tutumları ve destekleyici eğitim araçlarının eksik olması gibi nedenlerle bu değişime tam anlamıyla geçilemese de ters yüz öğrenme, öğrenme ortamlarının sınırlılıklarını önemli ölçüde ortadan kaldırmaktadır (Torun ve Dargut, 2015). Ters yüz öğrenme modelinde sınıf içi ve sınıf dışı öğrenme düzeyleri Şekil 1'de gösterilmiştir.

Geleneksel Öğrenme Modeli

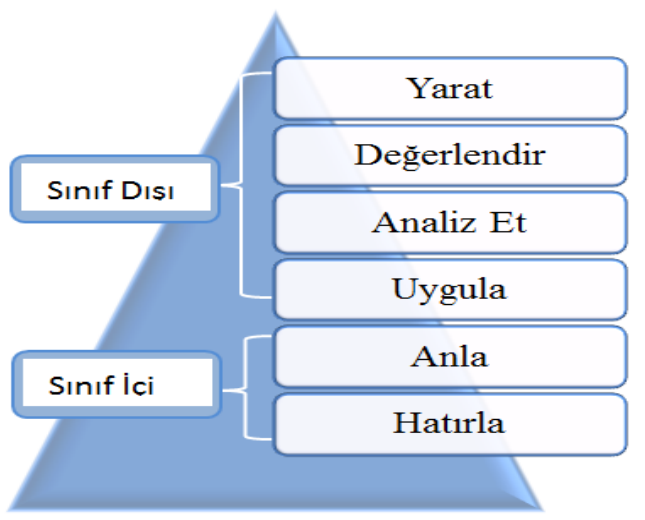

Ters Yüz Edilmiş Öğrenme Modeli

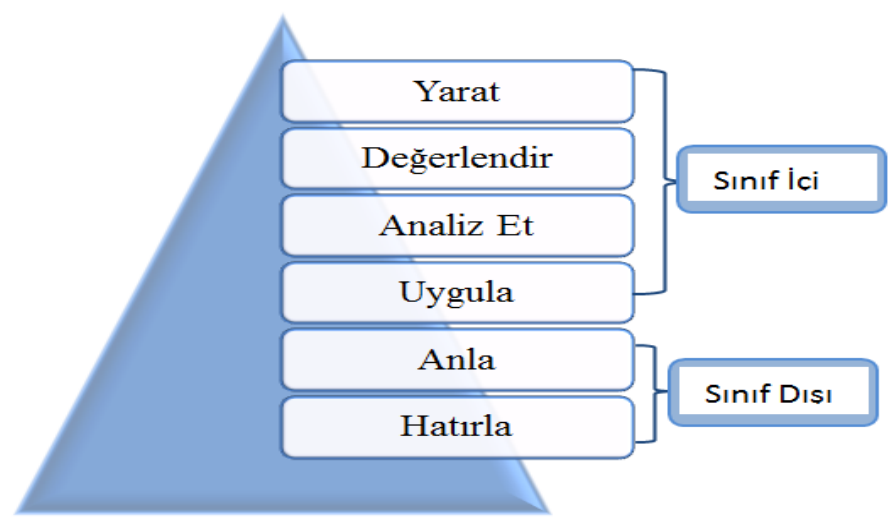

Şekil 1: Ters yüz öğrenmede sınıf içi ve sınıf dışı öğrenme düzeyleri (Hayırsever ve Orhan, 2018)

Ters yüz öğrenme modelinin çeşitli avantajları olduğu gibi bazı sınırlılıklarının da olduğu belirtilmektedir. Devlet okullarının teknolojik koşulları ve öğrencilerin ekonomik durumları göz önüne alınırsa her öğrencinin evde internet erişimine sahip olması da beklenemez. Ülkemizde sınıflarda etkileşimli tahtaların olması ve FATIH Projesi ile birlikte öğrencilere tablet dağıtılması eğitimde teknolojinin kullanılması açısından önemlidir, fakat henüz birçok okulda derslik ve ders materyallerinin, alt yapı sorunlarının olması da bu modelde bir sınırlılıktır. Diğer sınırlılık ise videoların hazırlanmasının zaman alması ve uğraştırıcı olması ve öğrencinin videoyu evde izleyip izlemediğinin takibinin zor olmasıdır. Ayrıca öğrenciler videoları ders dışı dinledikleri için anlamadıkları yerlerde soru soramama da sınırlılık olarak ifade edilebilir (Kardaş ve Yeşilyaprak, 2015).

Günümüzde öğretim süreçlerinin çoğunda öğrenci merkezli yöntemler önemsenmektedir. Teknolojinin yaygınlaşması ve eğitimde kullanım alanlarının artmasıyla öğrencilerin bilgiye kendilerinin ulaşmasını sağlamak araştırma ve sorgulamaya dayalı öğrenmeyi uygulamakla mümkün olmaktadır. Bu durumda, ters yüz öğrenmede araştırma ve sorgulamaya dayalı öğrenmenin kullanıldığını söylemek mümkündür.

Araştırma sorgulamaya dayalı öğrenme soru sorma, araştırma ve bilgileri analiz etme yoluyla öğrenme ve öğrendiklerini günlük yaşamda kullanılacak bilgiye dönüştürme sürecidir (Perry ve Richardson, 2001). Diğer bir ifadeyle, araştırma sorgulamaya dayalı öğrenme eleştirel düşünme ve kapsamlı sorgulama yoluyla problem çözmeye odaklanan öğrenci merkezli bir yaklaşımdır. Araştırma sorgulamaya dayalı öğrenme, öğrencilerin öğrenmek istediği ve bilgiyi elde etmek için sorular sormasına dayanan bir yöntemdir. Sorgulamaya dayalı öğrenme sürecinde öğrenciler, kendilerini aktif katılımcı, keşfetme sürecine istekli bir şekilde katılan, sorular soran, gözlem yapan, görevlerini ve öğrenme etkinliklerini planlayan olarak görmektedirler ve iletişimin farklı yollarını kullanmakta, çözümlemekte ve öğrenme süreçlerini eleştirmektedirler (Davis, 2005). Açıklamalardan da anlaşılacağı üzere, öğrenmenin oluşmasında sürekli ezber ve tekrar yapmak değil, sürekli sorgulayarak öğrencilerin bu süreci yaşamalarına olanak verilmelidir.

Günümüz eğitim anlayışında bilgiyi üreten, bilgiye ulaşan ve onu farklı alanlarda kullanabilen insanlara 
ihtiyaç duyulmaktadır. Modern eğitim anlayışımız öğretim süreçlerinin çoğunda öğrenci merkezli çalışmaları önemsemektedir. Araştırma sorgulamaya dayalı öğrenme, sorular sorarak gerçeği bulma esasına dayanmaktadır. Geleneksel eğitim anlayışında öğretmen bilgiyi aktaran bir bilge olarak görülürken araştırma sorgulamaya yönelik öğrenmede öğrencide merak uyandıran soruların olması ilk şarttır. Buna bağlı olarak öğrenen soru sorarak, bilgiye kendisi ulaşarak ve öğrenmede kendi sorumluluğunu alarak bilgiyi yapılandırmaktadır (Kardaş ve Yeşilyaprak, 2015).

Yukarıda belirtildiği üzere, ters yüz öğrenme modelinin ve araştırma sorgulamaya dayalı öğrenmenin ortak yönleri öğrencinin yaparak yaşayarak öğrenmesi ve öğretme-öğrenme sürecine aktif rol üstlenerek bilgiyi yapılandırmasıdır. Bu yönüyle öğrencilerin ters yüz öğrenme hazırbulunuşlukları ile araştırma ve sorgulamaya yönelik tutumlarının ilişkili olduğu düşünülmekte ve bunu belirlemeye yönelik araştırmalara ihtiyaç duyulmaktadır. Dolayısıyla, bu araştırmada ortaokul öğrencilerinin ters yüz öğrenme hazırbulunuşlukları ile araştırma sorgulamaya yönelik tutumları arasındaki ilişkiyi belirlemek amaçlanmaktadır. Bu çerçevede aşağıdaki sorulara cevap aranmıştır:

1. Öğrencilerin ters yüz öğrenme hazırbulunuşlukları ile araştırma sorgulamaya yönelik tutumları ne düzeydedir?

2. Öğrencilerin ters yüz öğrenme hazırbulunuşlukları ile araştırma sorgulamaya yönelik tutumları internet, bilgisayar, akıllı telefona sahip olma, okulun sosyo-ekonomik düzeyi ve aile gelir düzeyi değişkenlerine göre anlamlı farklılık göstermekte midir?

3. Öğrencilerin ters yüz öğrenme hazırbulunuşlukları ile araştırma sorgulamaya yönelik tutumları arasında anlamlı bir ilişki var mıdır?

Çağdaş eğitim anlayışında, öğrenci merkezli ve teknoloji destekli yeni model ve yaklaşımlar ortaya çıkmaktadır. Bu yaklaşımlar öğrenme sürecine öğrencinin aktif olarak katılması ve eğitime teknolojinin entegre edilmesi gibi durumları ön planda tutmaktadır. Öğrenci bilgiye öğrenme sorumluluğu üstlenerek ve araştırma, sorgulama yaparak ulaşmaya çalışmaktadır. Alanyazında ters yüz öğrenme (Bergmann, Overmyer ve Wilie, 2012; Bergman ve Sams, 2012; Boyraz, 2014; Çelik, Yıldırım ve Yıldırım, 2018; Duerdan, 2013; Engin, 2014; Engin ve Donancı 2014; Fer ve Cırık, 2006; Gençer, 2015; Gençer ve diğerleri, 2014; Kozikoğlu, 2019; Turan, 2015) ve araştırma sorgulamaya yönelik tutum (Babadoğan ve Gürkan, 2002; Çalışkan ve Turan, 2008; Karamustafaoğlu ve Havuz, 2016; Yaşar ve Duban, 2009) ile ilgili birçok çalışma bulunmaktadır. Fakat ortaokul öğrencilerinin ters yüz öğrenme hazırbulunuşlukları ile araştırma sorgulamaya yönelik tutumları arasındaki ilişkiye yönelik herhangi bir çalışmaya ulaşılmamıştır. Bu açıdan, bu çalışma ortaokul öğrencilerinin ters yüz öğrenme hazırbulunuşlukları ile araştırma sorgulamaya yönelik tutumları arasındaki ilişkiyi belirlemesi açısından önem taşımaktadır. Ayrıca, ters yüz öğrenmeyle ilgili alanyazındaki çalışmaların çoğunun ters yüz öğrenmenin çeşitli değişkenler üzerindeki etkisini inceleyen deneysel çalışmalar olduğu görülmektedir. Fakat ters yüz öğrenmenin etkili olarak uygulanabilmesi için materyal, olanaklar, öğrenci, öğretmen gibi faktörlerin buna uygun olması gerekmektedir. Dolayısıyla, bu çalışmanın bu değişkenlerden biri olan öğrencilerin ters yüz öğrenme hazırbulunuşluklarını belirlemesi açısından alanyazına katkı sağlayacağı düşünülmektedir. Bunun yanı sıra, bu çalışma ortaokul öğrencilerinin 21. yüzyıl öğrenen becerilerinden biri olan ve çağın gerektirdiği araştırma sorgulamaya yönelik tutumlarını belirlemesi açısından önemlidir.

\section{Yöntem}

\section{Araştırmanın Modeli}

$\mathrm{Bu}$ araştırma, ilişkisel tarama modelinde desenlenmiştir. İlişkisel tarama modelinde, iki veya daha fazla değişken (durumlar veya olaylar) arasındaki ilişkilerin varlığı ve/veya derecesi belirlenmektedir (Karasar, 2015). Bu araştırmada, ortaokul öğrencilerinin ters yüz öğrenme hazırbulunuşlukları ile araştırma sorgulamaya yönelik tutumları arasındaki ilişkiyi belirlemek amaçlanmaktadır. Dolayısıyla ilişkisel tarama modelinin araştırmada kullanılması uygun görülmektedir. 


\section{Evren ve Örneklem}

Bu araştırmanın çalışma evrenini, 2018-2019 eğitim yılında Van ili Tuşba merkez ilçesinde bulunan ortaokullarda (özel okullar hariç) okuyan 6., 7. ve 8. sınıf öğrencileri oluşturmaktadır. Bu araştırmada, tabakalı örnekleme yöntemi kullanılarak çalışma evreninden örneklem alma yoluna gidilmiştir. Tabakalı örnekleme yönteminde, araştırmada belirlenen değişkenlere göre çalışma evreni alt homojen gruplara ayrılmakta ve her gruptan seçkisiz olarak örnekleme alınacak bireyler belirlenmektedir (Büyüköztürk, Çakmak, Akgün, Karadeniz ve Demirel, 2016). Bu çalı̧̧mada, okulların sosyo-ekonomik düzeyi ve öğrencilerin sınıf düzeyi grup (tabaka) olarak ele alınmıştır. Dolayısıyla bu araştırmada, Tuşba ilçesindeki ortaokullar, uzman görüşüne göre yüksek sosyo-ekonomik gelişmişlik düzeyi, orta sosyo-ekonomik gelişmişlik düzeyi ve düşük sosyoekonomik gelişmişlik düzeyi olmak üzere üç gruba ayrılmıştır. Daha sonra, her bir gruptan bir ortaokul seçkisiz olarak seçilmiştir. Seçilen ortaokullarda okuyan 6., 7. ve 8. sınıf öğrencileri araştırmanın örneklemini oluşturmuş ve üç okuldan toplam 362 öğrenciye ulaşılmıştır. Bu araştırmanın çalışma evrenini, sadece Van ili Tuşba merkez ilçesinde bulunan ortaokullarda okuyan 6., 7. ve 8. sınıf öğrenciler oluşturduğu için çalışmanın genellenebilirliği sınırlıdır.

Örnekleme alınan ortaokul 6., 7. ve 8.sınıf öğrencilerinin 189'u (\%52.2) kız, 173'ü ise (\%47.8) erkektir. Düşük sosyo-ekonomik gelişmişlik düzeyindeki okuldan 120 (\%33.1), orta sosyo-ekonomik gelişmişlik düzeyindeki okuldan 120 (\%33.1) ve yüksek sosyo-ekonomik gelişmişlik düzeyindeki okuldan ise 122 (\%33.7) öğrenci örnekleme alınmıştır. Katılımcıların 121'i (\%33.4) 6. sınıf, 121'i (\%33.4) 7. sınıf ve 120'isi (\%33.2) ise 8. sinıf öğrencisidir.

\section{Veri Toplama Araçları}

Ortaokul öğrencileri için ters yüz öğrenme hazırbulunuşluk ölçeği. Durak (2017) tarafından geliştirilen 5’li Likert ölçeği, 26 maddeden oluşmaktadır. "Öğrenci kontrolü ve öz yönelimli öğrenme", "teknoloji öz yeterliği", "sınıf içi iletişim öz yeterliği", "öğrenme için motivasyon" ve "ön çalışma yapma" olmak üzere beş alt boyuttan oluşan ölçeğin Cronbach Alpha değeri .97 olarak hesaplanmış, alt boyutlara ilişkin iç tutarlılık katsayıları ise sırasıyla .94, .95, .89, .82, .70 olarak bulunmuştur (Durak, 2017). Bu çalışmada ise ölçeğin Cronbach Alpha değeri .84 olarak hesaplanmış, alt boyutlara ilişkin iç tutarlılık katsayıları ise sırasıyla .75, .84, $.80, .82$, .65 olarak bulunmuştur. Bu değerler, ölçme aracından elde edilen verilerin güvenilir olduğunu göstermektedir.

Ortaokul öğrencileri için araştırma sorgulamaya dönük tutum ölçeği. Korkmaz, Ozan ve Karamustafaoğlu (2016) tarafından geliştirilen 5'li Likert ölçeği, 13 maddeden ve merak duyma (4 madde), kaçınma (5 madde), değer verme (4 madde) alt boyutlarından oluşmaktadır. Ölçeğin Cronbach Alpha değeri .76 olarak bulunmuş, bu çalışmada da .76 olarak hesaplanmıştır. Bu değerler, ölçme aracından elde edilen verilerin güvenilir olduğunu göstermektedir.

\section{Verilerin Analizi}

Araştırmada, ortaokul öğrencilerinin ters yüz öğrenmeye ilişkin hazırbulunuşluklarını ve araştırma sorgulamaya dönük tutumlarını belirlemek üzere ölçek puanlarının aritmetik ortalamaları ve standart sapma değerleri incelenmiştir. Bu değerler; '1-1.79 arası' çok düşük, '1.80-2.59 arası' düşük, '2.60-3.39 arası' orta, '3.404.19 arası' yüksek ve '4.20-5.00 arası' ise çok yüksek düzey olarak yorumlanmıştır. Ortalamaların değişkenlere göre değişip değişmediğini belirlemek için normallik testi yapılmış ve veriler normal dağılım gösterdiği için evlerinde internet bağlantısı olup olmama durumu ve teknolojik araç gereçlere sahip olup olmama durumu değişkenleri için t-testi; okul sosyo-ekonomik düzeyi ve aile gelir düzeyi değişkenleri için ise ANOVA testi kullanılmıştır. Ayrıca, bağımlı değişkenler arasındaki ilişkileri incelemek için Pearson Çarpım Momentler Korelasyon Katsayılarına bakılmıştır. Bu katsayılar; '0.00-0.29 arası' düşük, '0.30-0.69 arası' orta ve '0.70 ve üzeri' ise yüksek düzeyde ilişki olarak yorumlanmıştır (Büyüköztürk ve diğerleri, 2016). 


\section{Bulgular}

Araştırmanın birinci alt problemine ilişkin ortaokul öğrencilerinin ölçeklere verdikleri yanıtlara göre hesaplanan betimsel istatistikler Tablo I'de sunulmuştur.

Tablo I

Ortaokul Öğrencilerinin Ölçeklere Verdikleri Yanıtlara Göre Hesaplanan Betimsel İstatistikler

\begin{tabular}{lllc}
\hline Ölçekler & Alt boyutlar & $\bar{X}$ & \multicolumn{1}{c}{$S$} \\
\hline Ters Yüz Öğrenme Hazırbulunuşluk & & 3.48 & 0.68 \\
& Öğrenme kontrolü ve öz yönelimli öğrenme & 3.68 & 0.65 \\
& Teknoloji yeterliği & 2.96 & 0.98 \\
& Sınıf içi iletişim öz yeterliği & 3.93 & 1.23 \\
& Öğrenme için motivasyon & 3.93 & 1.28 \\
& Ön çalışma yapma & 3.46 & 1.17 \\
\hline Araştırmaya Sorgulamaya Yönelik Tutum & & 3.84 & 0.63 \\
\hline
\end{tabular}

Tablo I incelendiğinde, ortaokul öğrencilerinin ters yüz öğrenme hazırbulunuşluklarının toplam ölçekte ( $\bar{X}=3.48$ ) ve ölçeğin alt boyutları olan öğrenci kontrolü ve öz yönelimli öğrenmelerinin ( $\bar{X}=3.68)$, sinıf içi iletişim öz yeterliliklerinin $(\bar{X}=3.93)$, öğrenme motivasyonlarının $(\bar{X}=3.93)$ ve ön çalışma yapmalarının $(\bar{X}=3.46)$ yüksek düzeyde olduğu, teknoloji yeterliliğinin ise $(\bar{X}=2.96)$ orta düzeyde olduğu görülmektedir. Ayrıca, ortaokul öğrencilerinin araştırma sorgulamaya yönelik tutumlarının yüksek düzeyde olduğu saptanmıştır.

Araştırmanın ikinci alt problemi olan “Ortaokul öğrencilerinin ters yüz öğrenme hazırbulunuşlukları ve araştırma sorgulamaya yönelik tutumları internet, bilgisayar, akıllı telefona sahip olma, okulun sosyoekonomik düzeyi ve aile gelir düzeyi değişkenlerine göre anlamlı farklılık göstermekte midir?" sorusuna yönelik ortaokul öğrencilerinin ters yüz öğrenme hazırbulunuşlukları ve araştırma sorgulamaya yönelik tutumlarının internete sahip olma durumlarına göre $t$ testi sonuçları Tablo II'de sunulmuştur.

Tablo II

Ortaokul Öğrencilerinin Ters Yüz Öğrenme Hazırbulunuşluk ve Araştırma-Sorgulamaya Yönelik Tutumlarının Internete Sahip Olma Durumuna Göre t Testi Sonuçları

\begin{tabular}{|c|c|c|c|c|c|c|c|}
\hline Ölçekler & Internet & Sayı & $\bar{X}$ & s & sd & $\mathbf{t}$ & p \\
\hline \multirow{2}{*}{ Ters Yüz Öğrenme Hazırbulunuşluk } & Evet & 142 & 3.68 & 0.74 & \multirow{2}{*}{359} & \multirow{2}{*}{4.61} & \multirow{2}{*}{.000} \\
\hline & Hayır & 219 & 3.35 & 0.61 & & & \\
\hline \multirow{2}{*}{ Araştırma Sorgulamaya Yönelik Tutum } & Evet & 142 & 3.94 & 0.65 & \multirow{2}{*}{360} & \multirow{2}{*}{2.45} & \multirow{2}{*}{.015} \\
\hline & Hayır & 220 & 3.77 & 0.60 & & & \\
\hline
\end{tabular}

Tablo II'de görüldüğü üzere, ortaokul öğrencilerinin ters yüz öğrenme hazırbulunuşlukları $\left(\mathrm{t}_{(359)}=4.61\right.$, $\mathrm{p}>.05)$ ve araştırma sorgulamaya yönelik tutumları $\left(\mathrm{t}_{(360)}=2.45, \mathrm{p}>.05\right)$ internete sahip olma durumlarına göre internete sahip olanlar lehine anlamlı farklılık göstermektedir.

Ortaokul öğrencilerinin ters yüz öğrenme hazırbulunuşlukları ve araştırma sorgulamaya yönelik tutumlarının bilgisayara sahip olma durumuna göre $t$ testi sonuçları Tablo III'te sunulmuştur.

\section{Tablo III}

Ortaokul Öğrencilerinin Ters Yüz Öğrenme Hazırbulunuşluk ve Araştırma-Sorgulamaya Yönelik Tutumlarının Bilgisayara Sahip Olma Durumuna Göre t Testi Sonuçları

\begin{tabular}{|c|c|c|c|c|c|c|c|}
\hline Ölçekler & Bilgisayar & Say1 & $\bar{X}$ & $\mathbf{s}$ & sd & $t$ & $p$ \\
\hline \multirow{2}{*}{ Ters Yüz Öğrenme Hazırbulunuşluk } & Evet & 80 & 3.71 & 0.66 & \multirow{2}{*}{359} & \multirow{2}{*}{3.48} & \multirow{2}{*}{.001} \\
\hline & Hayır & 281 & 3.42 & 0.68 & & & \\
\hline \multirow{2}{*}{ Araştırma Sorgulamaya Yönelik Tutum } & Evet & 80 & 3.88 & 0.67 & \multirow{2}{*}{360} & \multirow{2}{*}{0.69} & \multirow{2}{*}{.490} \\
\hline & Hayır & 282 & 3.83 & 0.61 & & & \\
\hline
\end{tabular}

Tablo III'te görüldüğ̈̈ üzere, ortaokul öğrencilerinin ters yüz öğrenme hazırbulunuşluklarının (t $(359)=3.48$, $\mathrm{p}<.05$ ) bilgisayara sahip olma durumuna göre bilgisayara sahip olanlar lehine anlamlı fark gösterdiği, ancak araştırma sorgulamaya yönelik tutumlarının $(\mathrm{t}(360)=0.69, \mathrm{p}>.05)$ bigisayara sahip olma durumlarına göre anlamlı farklılı̆̆ın olmadığı belirlenmiştir.

Ortaokul öğrencilerinin ters yüz öğrenme hazırbulunuşlukları ve araştırma sorgulamaya yönelik 
tutumlarının akıllı telefona sahip olma durumuna göre $t$ testi sonuçları Tablo IV'te verilmiştir.

Tablo IV

Ortaokul Öğrencilerinin Ters Yüz Öğrenme Hazırbulunuşluk ve Araştırma-Sorgulamaya Yönelik Tutumlarının Akıllı Telefona Sahip Olma Durumuna Göre t Testi Sonuçları

\begin{tabular}{|c|c|c|c|c|c|c|c|}
\hline Ölçekler & Akıllı Telefon & Sayı & $\bar{X}$ & $\mathbf{s}$ & sd & $\mathbf{t}$ & $\mathrm{p}$ \\
\hline \multirow{2}{*}{ Ters Yüz Öğrenme Hazırbulunuşluk } & Evet & 112 & 3.65 & 0.78 & \multirow{2}{*}{359} & \multirow{2}{*}{3.22} & \multirow{2}{*}{.001} \\
\hline & Hayır & 249 & 3.40 & 0.61 & & & \\
\hline \multirow{2}{*}{ Araştırma Sorgulamaya Yönelik Tutum } & Evet & 113 & 3.87 & 0.62 & \multirow{2}{*}{360} & \multirow{2}{*}{0.67} & \multirow{2}{*}{.503} \\
\hline & Hayır & 249 & 3.82 & 0.63 & & & \\
\hline
\end{tabular}

Tablo IV'te görüldüğü üzere, ortaokul öğrencilerinin ters yüz öğrenme hazırbulunuşluklarının (t $(359)=$ 3.22, $\mathrm{p}<.05)$ akıllı telefona sahip olma durumuna göre akıllı telefona sahip olanlar lehine anlamlı fark gösterdiği, ancak araştırma sorgulamaya yönelik tutumlarının $(t(360)=0.67, p>.05)$ akıllı telefona sahip olma durumuna göre anlamlı farklılığın olmadığı belirlenmiştir.

Ortaokul öğrencilerinin ters yüz öğrenme hazırbulunuşlukları ve araştırma sorgulamaya yönelik tutumlarının okul sosyo-ekonomik düzeyine göre ANOVA testi sonuçları Tablo V'te sunulmuştur.

Tablo V

Ortaokul Öğrencilerinin Ters Yüz Öğrenme Hazırbulunuşluk ve Araştırma-Sorgulamaya Yönelik Tutumlarının Okulun Sosyo-Ekonomik Düzeyine Göre ANOVA Sonuçları

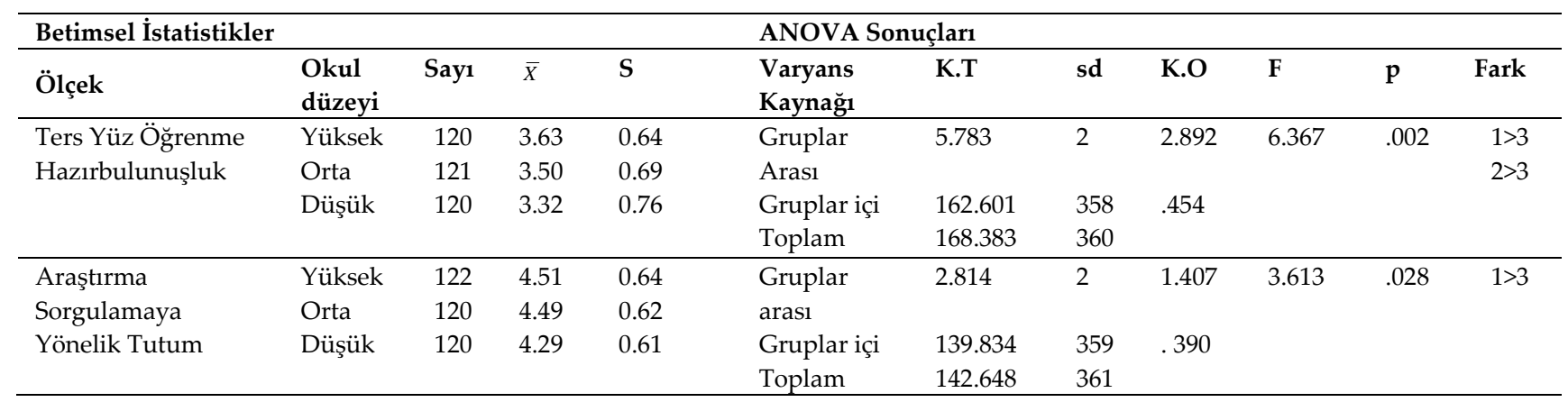

1: Yüksek sosyo-ekonomik gelişmişlik düzeyi, 2: Orta sosyo-ekonomik gelişmişlik düzeyi, 3: Düşük sosyo-ekonomik gelişmişlik düzeyi

Tablo V'te görüldüğü üzere, ortaokul öğrencilerinin ters yüz öğrenme hazırbulunuşluklarında $\left(\mathrm{F}_{(2,358)}=6.367, \mathrm{p}<.05\right)$ okulun sosyo-ekonomik gelişmişlik düzeyine göre yüksek ile orta ve düşük sosyoekonomik gelişmişlik düzeyine sahip okullar arasında yüksek sosyo-ekonomik gelişmişlik düzeyine sahip okullar lehine anlamlı farklılık bulunmaktadır. Ayrıca, öğrencilerin araştırma sorgulamaya yönelik tutumları $\left(\mathrm{F}_{(2,359)}=3.613, \mathrm{p}<.05\right)$ yüksek ile düşük sosyo-ekonomik gelişmişlik düzeyindeki okullar arasında yüksek sosyoekonomik gelişmişlik düzeyindeki okullar lehine anlamlı farklılık gösterdiği görülmektedir.

Ortaokul öğrencilerinin ters yüz öğrenme hazırbulunuşlukları ve araştırma sorgulamaya yönelik tutumlarının öğrencilerin aile gelir düzeyine göre ANOVA sonuçları Tablo VI'da sunulmuştur.

Tablo VI

Ortaokul Öğrencilerinin Ters Yüz Öğrenme Hazırbulunuşluk ve Araştırma-Sorgulamaya Yönelik Tutumlarının Aile Gelir Düzeyine Göre ANOVA Sonuçları

\begin{tabular}{|c|c|c|c|c|c|c|c|c|c|c|c|}
\hline Ölçek & $\begin{array}{l}\text { Aile } \\
\text { düzeyi }\end{array}$ & Sayı & $\bar{X}$ & $S$ & $\begin{array}{l}\text { Varyans } \\
\text { Kaynağ1 }\end{array}$ & K.T & sd & K.O & F & p & Fark \\
\hline Ters Yüz & $0-1499$ & 97 & 3.37 & 0.73 & Gruplar & 5.970 & 3 & 1.990 & 4.374 & .005 & $4>1$ \\
\hline Öğrenme & $1500-2499$ & 123 & 3.45 & 0.65 & arası & & & & & & $4>2$ \\
\hline \multirow[t]{3}{*}{ Hazırbulunuşluk } & $2500-3499$ & 84 & 3.48 & 0.58 & Gruplar & 162.414 & 357 & .455 & & & \\
\hline & 3500 ve üzeri & 57 & 3.76 & 0.77 & içi & & & & & & \\
\hline & & & & & Toplam & 168.383 & 360 & & & & \\
\hline Araştırma & $0-1499$ & 97 & 3.91 & 0.63 & Gruplar & 2.181 & 3 & .727 & 1.853 & 137 & \\
\hline Sorgulamaya & $1500-2499$ & 123 & 3.81 & 0.64 & aras1 & & & & & & \\
\hline \multirow[t]{3}{*}{ Yönelik Tutum } & $2500-3499$ & 85 & 3.72 & 0.61 & Gruplar & 140.467 & 358 & .392 & & & \\
\hline & 3500 ve üzeri & 57 & 3.93 & 0.61 & içi & & & & & & \\
\hline & & & & & Toplam & 142.648 & 361 & & & & \\
\hline
\end{tabular}

1: 0-1499 TL, 2: 1500-2499 TL, 3: 2.500-3499 TL, 4: 3.500 ve üzeri TL 
Tablo VI'da görüldüğü üzere, ortaokul öğrencilerinin ters yüz öğrenme hazırbulunuşlukları $\left(\mathrm{F}_{(3,357)=}\right.$ 4.374, $\mathrm{p}<.05$ ) aile gelir düzeyine göre ailesi $3500 \mathrm{TL}$ ve üzeri gelire sahip olan öğrenciler ile ailesi 0-2499 TL gelire sahip olan öğrenciler arasında ailesi $3500 \mathrm{TL}$ ve üzeri gelire sahip olan öğrenciler lehine anlamlı farklılık olduğu belirlenmiştir. Öte yandan öğrencilerin araştırma sorgulamaya yönelik tutumlarında $\left(\mathrm{F}_{(3,358)}=1.853, \mathrm{p}\right.$ $>.05$ ) aile gelir düzeyine göre anlamlı farklılık olmadığı belirlenmiştir.

Araştırmanın üçüncü alt problemi olan “Ortaokul öğrencilerinin ters yüz öğrenme hazırbulunuşlukları ile araştırma sorgulamaya yönelik tutumları arasında anlamlı bir ilişki var mıdır?" sorusuna ilişkin "ters yüz öğrenme hazırbulunuşluk" ve "araştırma sorgulamaya yönelik tutum" değişkenleri arasındaki ilişkiyi belirlemeye yönelik Pearson Çarpım Momentler Korelasyon Katsayıları Tablo VII'de sunulmuştur.

Tablo VII

Bă̆ımlı Değiş̧kenlere İlişkin Pearson Çarpım Momentler Korelasyon Katsayıları

\begin{tabular}{|c|c|c|c|c|c|c|c|}
\hline Değişkenler & (1) & (2) & (3) & (4) & (5) & (6) & (7) \\
\hline 1. Araştırma Sorgulamaya Yönelik Tutum & 1.000 & $.426^{* *}$ & $.392^{* *}$ & $.206^{* *}$ & $.345^{* *}$ & $.342^{* *}$ & $.297^{* *}$ \\
\hline 2. Ters Yüz Öğrenme Hazırbulunuşluk (toplam) & & 1.000 & $.764^{* *}$ & $.775^{* *}$ & $.620^{* *}$ & $.611^{* *}$ & $.654^{* *}$ \\
\hline 3. Öğrenci kontrolü ve öz yönelimli öğrenme & & & 1.000 & $.379^{* *}$ & $.471^{* *}$ & $.408^{* *}$ & $.470^{* *}$ \\
\hline 4. Teknoloji yeterliği & & & & 1.000 & $.170^{* *}$ & $.257^{* *}$ & $.475^{* *}$ \\
\hline 5. Sınıf içi iletişim öz yeterliği & & & & & 1.000 & $.380^{* *}$ & $.285^{* *}$ \\
\hline 6. Öğrenme için motivasyon & & & & & & 1.000 & $.342^{* *}$ \\
\hline 7. Ön çalışma yapma & & & & & & & 1.000 \\
\hline
\end{tabular}

Tablo VII verilerine göre, ortaokul öğrencilerinin araştırma sorgulamaya yönelik tutumları ile ters yüz öğrenme hazırbulunuşlukları arasında orta düzeyde, pozitif ve anlamlı bir ilişkinin olduğu $(\mathrm{r}=.426, \mathrm{p}<.01)$ belirlenmiştir. Ayrıca, öğrencilerin araştırma sorgulamaya yönelik tutumları ile ters yüz öğrenme hazırbulunuşluğunun alt boyutları olan öğrenci kontrolü ve öz yönelimli öğrenme ( $r=.392, p<0.01)$, sinıf içi iletişim öz yeterliği $(\mathrm{r}=.345$, $\mathrm{p}<0.01)$ ve öğrenme için motivasyon $(\mathrm{r}=.342, \mathrm{p}<0.01)$ arasında orta düzeyde, pozitif ve anlamlı bir ilişkinin olduğu, teknoloji yeterliği $(\mathrm{r}=.206, \mathrm{p}<0.01)$ ve ön çalışma yapma $(\mathrm{r}=.297, \mathrm{p}<0.01)$ arasında ise düşük düzeyde, pozitif ve anlamlı bir ilişkinin olduğu belirlenmiştir.

\section{Sonuç ve Tartışma}

Bilişim teknolojilerinde meyadana gelen değişim ve gelişmeler, her alanda olduğu gibi eğitim alanında da önemli gelişmelerin kaydedilmesini kolaylaştırmıştır (Odabaşı, 2010). Mevcut çağın gerektirdikleri ve bu çağın öğrenci profili dikkate alındığında, mevcut uygulamalardan farklı olarak yenilikçi öğretim modellerine gereksinim duyulmaktadır. Dolayısıyla, öğretmenin 40 dakika boyunca dersi anlatması ve öğrencilerin bu süre boyunca ders dinlemesi mümkün görünmemektedir. Günümüz çağında öğrenciler daha farklı öğrenme yöntemlerine yönelmekte ve bu doğrultuda öğretmenlerin üstlenmesi gereken görev ve sorumluluklar da farklılık göstermektedir. Öğretmenlerden "her şeyi bilme, bilgiyi aktarma, tahtada sürekli ders anlatarak öğrenciden daha aktif olma" gibi rollerin yerine "öğrenme sürecine rehberlik etme, eğitim teknolojilerini iyi kullanma, öğrencilerin bireysel ihtiyaçlarına uygun öğrenme yöntemlerinden yararlanma" gibi roller beklenmektedir. Bu da ters yüz öğrenme ve bu modelle ilişkili olan araştırma sorgulama yapmakla mümkün olmaktadir.

Ortaokul öğrencilerinin ters yüz öğrenme hazırbulunuşluğu ve araştırma sorgulamaya yönelik tutumları arasındaki ilişkinin incelendiği bu araştırmada, ortaokul öğrencilerinin ters yüz öğrenme hazırbulunuşluklarının ve araştırma sorgulamaya yönelik tutumlarının yüksek düzeyde olduğu sonucuna ulaşılmıştır. Öğrencilerin ters yüz öğrenme hazırbulunuşluğunun alt boyutları olan sınıf içi iletişim öz yeterliği, öğrenme kontrolü ve öz yönelimli öğrenme, öğrenme için motivasyon ve ön çalışma yapma becerilerinin yüksek düzeyde; teknoloji yeterliliklerinin ise orta düzeyde olduğu ortaya çıkmıştır. Alanyazında ters yüz öğrenme hazırbulunuşluğu ve araştırma sorgulamaya yönelik tutumun düzeyini belirlemeye yönelik çalışmalara rastlanmamıştır. Bu çalışma sonuçlarından hareketle, ortaokul öğrencilerinin öğretme-öğrenme süreçlerinde ters yüz öğrenme modelinin uygulanabilmesi için gerekli olan becerilere yeterli düzeyde sahip oldukları ve dolayısıyla ters yüz öğrenmeye hazır oldukları söylenebilir. Ayrıca, öğrencilerin ters yüz öğrenme modeli için de gerekli olan araştırma ve sorgulama yapmaya ilişkin olumlu 
tutum sergilediklerini söylemek mümkündür. Ters yüz edilmiş öğrenme modeli öğrenci merkezlidir. Her bir öğrenci sınıfa gelmeden önce öğrenme materyalini temel düzeyde anlama sorumluluğuna sahiptir ve bunun sonucunda sınıf tartışmalarına katılır ve ilgi gösterir (McLaughlin ve diğerleri, 2014). Bu nedenle, ters yüz öğrenmede öğrenme sürecinin etkililiği açısından öğrencilerin öz yönelimli öğrenme, motivasyon, sınıf içi iletişim öz yeterliği, ön çalışma yapma açısından gerekli yeterliklere sahip olmaları gerekmektedir. Bu çalışmada, öğrencilerin bu yeterliklere sahip olduklarını düşünmeleri ters yüz öğrenmenin uygulanabilmesi açısından önem taşımaktadır. Öte yandan, öğrencilerin teknoloji yeterliklerinin orta düzeyde çıkması, bir başka deyişle teknoloji yeterliklerinin istenilen düzeyde olmaması olumsuz bir sonuç olarak değerlendirilebilir. Bu durum, öğrencilerin teknolojik olanaklara erişim, olanaklar ve almış oldukları eğitim ile ilişkilendirilebilir. Araştırma ve sorgulamaya dayalı öğrenme, öğrencinin doğrudan katıldığı etkinliklerle araştırma yaparak öğrenmesini sağlamaktadır (Bozkurt Altan, 2017). Bu durumda, öğrencilerin araştırma sorgulamaya yönelik olumlu tutum sergilemeleri, hem öğrencilerin öğretme-öğrenme sürecinde aktif olmaları hem de ters yüz öğrenme modelinin uygulanabilirliği açısından olumlu bir sonuç olarak düşünülebilir.

Araştırmada, evinde internet bağlantısı olan öğrencilerin ters yüz öğrenme hazırbulunuşluklarının ve araştırma sorgulamaya yönelik tutumlarının daha yüksek düzeyde olduğu belirlenmiştir. Ayrıca, bilgisayar ve akıllı telefona sahip olan öğrencilerin ters yüz öğrenme hazırbulunuşluklarının daha yüksek düzeyde olduğu, ancak öğrencilerin araştırma sorgulamaya yönelik tutumlarının bilgisayar ve akıllı telefona sahip olma durumuna göre değişmediği sonucuna ulaşılmıştır. Bu durumda, internet erişimine ve teknolojik araç gereçlere sahip olan öğrencilerin ters yüz öğrenmeye ilişkin daha hazır olduklarını söylemek mümkündür. Öte yandan internet erişimi öğrencilerin araştırma ve sorgulamaya ilişkin yönelimini olumlu desteklerken teknolojik araç gereçlere sahip olan ve olmayan öğrencilerin araştırma ve sorgulamaya ilişkin tutumlarının benzer olduğu söylenebilir. Bu araştırma sonuçlarıyla paralel olarak Kurt, Çoklar, Kılıçer ve Yıldırım (2008) tarafından yapılan çalışmada, bilgisayara sahip olmanın ve internete erişiminin öğrencilerin eğitim teknolojisi standartlarına ilişkin becerilerinin gelişmesinde önemli bir rol oynadığı belirlenmiştir. Alanyazında ters yüz öğrenme hazırbulunuşluğunun ve araştırma sorgulamaya yönelik tutumun internete ve teknolojik araçlara sahip olma durumuna göre ele alındığı bir çalışmaya rastlanmamıştır. Fakat alanyazında belirtildiği üzere, teknoloji materyaller aracılığıyla öğrenmeyi kolaylaştırmakta ve kalıcılığı artırmaktadır. Günümüz çağında sabit bir sunu tekniğinin kullanılmasından ziyade teknoloji ve internet destekli güncel yaklaşımların kullanılması bir ihtiyaç haline gelmiştir. Buna ek olarak, araştırmalar, video tabanlı derslerin, öğrencilerin dikkatini içeriğe daha iyi odaklayarak öğrencileri motive etmek için kullanılabileceğini göstermiştir (Choi ve Johnson, 2005). Nitekim eğitim teknolojileri ile ilgili alanyazındaki araştırmalar incelendiğinde, öğretmeöğrenme ortamlarında eğitimin teknolojiyle bütünleştirildiği ve farklı öğretim yöntemlerinin kullanıldığı ön plana çıkmaktadır (Aydın, 2016; Bell, 2015; Farah, 2014). Bu öğretim modellerinden biri olan ters yüz öğrenme de özellikle ders dışı etkinliklerde (video, öğrenme portalları vb.) teknlojiden faydalanılmaktadır. Bu anlamda ters yüz edilmiş öğrenmenin belirli ölçüde internet erişimi ve teknolojik araç gereçlerin kullanımını gerektirdiğini söylemek yanlış olmayacaktır. Dolayısıyla internet erişimine ve teknolojik araç gereçlere sahip olan öğrencilerin ters yüz öğrenme açısından hazırbulunuşluklarının artması beklenen bir sonuç olarak değerlendirilebilir. Ayrıca, evinde internet erişimine sahip olan öğrencilerin araştırma ve sorgulamaya ilişkin daha olumlu tutum geliştirmeleri üzerinde internetin önemli bir bilgi kaynağı olarak kullanıldığı günümüzde bilgiye erişmede sağladığı olanak ve kolaylıklar önemli bir etken olarak görülebilir.

Araştırmada, yüksek sosyo-ekonomik gelişmişlik düzeyine sahip okullarda öğrenim gören ortaokul öğrencilerinin ters yüz öğrenme hazırbulunuşluklarının ve araştırma sorgulamaya yönelik tutumlarının daha yüksek düzeyde olduğu belirlenmiştir. Ayrıca, aile gelir düzeyi yüksek olan öğrencilerin ters yüz öğrenme hazırbulunuşluklarının daha yüksek olduğu; fakat öğrencilerin araştırma sorgulamaya yönelik tutumlarının aile gelir düzeyine göre anlamlı düzeyde değişmediği belirlenmiştir. Bu durumda, sosyo-ekonomik gelişmişlik düzeyi yüksek okullarda öğrenim gören ve aile gelir düzeyi yüksek olan öğrencilerin ters yüz öğrenmeye daha hazır oldukları, sosyo-ekonomik gelişmişlik düzeyi yüksek okullarda okuyan öğrencilerin aynı zamanda araştırma ve sorgulamaya yönelik daha olumlu tutuma sahip oldukları söylenebilir. Ailenin sosyo-ekonomik düzeyi, öğrencilerin okula katılım süreçleri ve okul başarısı üzerinde etkilidir (Tansel, 2002). Sosyo-ekonomik düzeyin yüksek olması, öğrencilerin öğrenme sürecini birçok açıdan kolaylaştırmaktadır. 
Örneğin; bu tür ailelerin çocuklarına sundukları mayeryal, fırsatlar ve olanaklar çocuğun bilişsel, duyuşsal, psiko-motor ve sosyo-kültürel gelişimini desteklemektedir (Teachman, 1987). Öte yandan, düşük sosyoekonomik düzeye sahip ailelerin yaşadıkları bölge, çevre ve ortamın özellikleri çocuğun gelişimini destekleyecek etkenlerden yoksundur. Ailenin sosyo-ekonomik ve gelir düzeyinden etkilenen bir diğer faktör çocuğun kaynaklara, araç ve gereçlere ulaşım şansıdır. Sosyo-ekonomik ve gelir düzeyi yüksek aileler çocuklarına her türlü materyali temin edebilirken, sosyo-ekonomik ve gelir düzeyi düşük ailleler bu bakımdan yetersiz kalabilmektedir (Çiftçi ve Çağlar, 2014). Dolayısıyla, sosyo-ekonomik gelişmişlik düzeyinin ve bununla ilişkili olarak aile gelir düzeyinin çocuğun hazırbulunuşluk, tutum ve becerilerinin gelişiminde belirleyici olduğunu söylemek mümkündür. Sonuç olarak, ilgili alanyazın ve bu araştırma sonuçlarından hareketle, aile gelir düzeyi ile okulun sosyo-ekonomik gelişmişlik düzeyinin ilişkili olduğu düşünülerek sosyo-ekonomik gelişmişlik düzeyi yüksek okullarda öğrenim gören ve aile gelir düzeyi yüksek olan öğrencilerin ters yüz öğrenmeye daha hazır olmaları ve araştırma sorgulamaya yönelik daha olumlu tutum geliştirmelerinin, ailenin ve çevrenin bilgiye erişme açısından sunduğu olanaklar (internet ve teknolojik araç gereçler), sağladığı fırsatlar ve öğrenme ortamı ile ilişkili olduğu düşünülebilir.

Araştırmada, ortaokul öğrencilerinin ters yüz öğrenme hazırbulunuşlukları ile araştırma sorgulamaya yönelik tutumları arasında olumlu ilişkilerin olduğu sonucuna varılmıştır. Dolayısıyla, öğrencilerin araştırma sorgulamaya yönelik tutumları arttıkça ters yüz öğrenmeye ilişkin hazırbulunuşluklarının da arttığı söylenebilir. Ters yüz öğrenmenin gerektirdiği öğrenmenin sorumluluğunu alma, öğrencinin bilgiye kendisinin ulaşmasını sağlama gibi özellikleri yapılandırmacı yaklaşımın şartlarını taşıyan araştırma sorgulama ile bağlantılıdır. Yapılandırmacı yaklaşım bu yönüyle öğrenciyi bilgininin pasif alıcısı olarak gören davranışçı yaklaşımdan keskin bir şekilde ayrılmaktadır (Carwile, 2007; Rovai, 2004). Bireyler bilgiyi araştıran ve sorgulayan aktif öğrenenlerdir (Yurdakul, 2010). Yapılandırmacı öğrenme ortamı, öğretmenlerin öğrencilerin eleştirel ve yaratıcı düşünme, problem çözme becerilerini geliştirebilecek deneyimler kazanmalarını sağlayacak öğrenme yaşantılarını oluşturabilecekleri, öğrenen merkezli aktivitelere olanak sağlayan bir ortamdır (Neo ve Neo, 2009). Yapılandırmacı sınıf ortamında öğretmen bilginin tek otoritesi olmak yerine öğrencilerin araştırmalarına yol gösteren ve tecrübeler edinmelerini sağlayan kişidir (Nikitina, 2010). Bu sayede, iyi planlanmış bir öğrenme ortamında öğrenciler "nasıl öğrenileceğini" öğrenirler (Iofciu, Miron ve Antohe, 2011). Araştırma sorgulamaya yönelik öğrenmede ve ters yüz edilmiş sınıflarda öğrencilerin geleneksel öğrenme yöntemleri olarak addedilen ezbere dayalı öğretim veya sürekli tekrar yapılması değil, aksine bilgiyi sürekli olarak sorgulama yöntemiyle temellendirilmeleri ve öğrenci zemininde bu süreci yaşamaları görüşü hakimdir. Her iki öğrenmede temel alınan noktalar öğrencinin bireysel görüşleri ve istekleri doğrultusunda bir öğrenme sürecini merkeze alması, sadece okula ve sınıf içi öğrenmeye bağımlı değil, sınıf dışı öğrenmeye ağırlık vermesi ve bu bilgileri öğrencilerin istekleri doğrultusunda devam ettirmesi olarak değerlendirilebilir. Ayrıca her iki yöntem de öğrencinin yaparak yaşayarak öğrenmesi gerektiği düşüncesi çevresinde hemfikirdir. Dolayısıyla, ters yüz öğrenme modelinde öğrencilerin kuramsal bilgiyi sınıf dışında hem öğretmen desteği hem de kendi çabalarıyla öğrenmesi temel alındığı için öğrencilerin sahip oldukları araştırma sorgulama beceri ve tutumlarının bu modele ilişkin hazırbulunuşluğu olumlu etkilediği düşünülebilir.

Sonuç olarak araştırmada ortaokul öğrencilerinin ters yüz öğrenme hazırbulunuşlukları ve araştırma sorgulamaya yönelik tutumlarının olumlu yönde ilişkili olduğu, ayrıca internet, teknolojik araç gereçler, aile gelir düzeyi ve okulun sosyo-ekonomik gelişmişlik düzeyi gibi değişkenlere göre öğrencilerin ters yüz öğrenme hazırbulunuşlukları ve araştırma sorgulamaya yönelik tutumlarının farklılaştığı görülmektedir. Bu araştırma sonuçları doğrultusunda, öğrencilerin bilişim teknolojilerini sürekli kullanabilme imkânının ters yüz öğrenme hazırbulunuşluğunu artırdığı sonucu göz önünde bulundurularak öğrencilerin mümkün olabildiğince bilgisayar ve interneti doğru şekilde ve öğrenme amaçlı kullanabilmeleri sağlanabilir. Ters yüz öğrenme açısından, gerekli internet erişimine sahip olmayan öğrenciler için ders içerikleri bir DVD'ye aktarılabilir. Aynı zamanda teknoloji yeterliği az olan öğrenciler internet ve teknoloji kullanımı konusunda cesaretlendirilmelidir. Ters yüz öğrenme ve araştırma sorgulamaya dönük yaklaşım ve modellerle öğretimi farklılaştırmanın öneminden hareketle, bu modellerin ülkemizde kullanımını artırmaya yönelik öğretmenlerin bu yaklaşımları öğretimde nasıl işe koşacaklarına ilişkin bilgilendirilmeleri önerilebilir. 


\section{Kaynaklar}

Akkoyunlu, B. ve Gündüz, A. Y. (2015, Nisan). Dönüştürülmüş (flipped) sınıflar uygulaması: Bir ders örneği. 5th International Symposium of Policies and Issues on Teacher Education, Bakü, Azerbaycan.

Aydın, B. (2016). The effects of flipped classroom model on academic achievement, homework/task stress level and transfer of learning (Yayınlanmamış yüksek lisans tezi). Süleyman Demirel Universitesi, Isparta.

Babadoğan, C. ve Gürkan, T. (2002). Sorgulayıcı öğretim stratejisinin akademik başarıya etkisi. Eğitim Bilimleri ve Uygulama Dergisi, 1(2), 147-160.

Bell, M. R. (2015). An investigation of the impact of a flipped classroom instructional approach on high school students' content knowledge and attitudes toward the learning environment (Yayımlanmamıs yüksek lisans tezi). Brigham Young University, Utah.

Bergmann, J., Overmyer, J. ve Wilie, B. (2012). The flipped class: Myths versus reality. The Daily Riff [Blog yazısı]. Erişim adresi: https://kmtrosclair.files.wordpress.com/2015/06/the-flipped-class-myths-vsreality-the-daily-riff-be-smarter-about-education.pdf

Bergmann, J. ve Sams, A. (2012). Flip your classroom: Reach every student in every class every day. Alexandria, VA: International Society for Technology in Education.

Bishop, J. L. ve Verleger, M. A. (2013). The flipped classroom: A survey of the research. 120th American Society for Engineering Education Annual Conference and Exposition, 30, 1-18.

Boyraz, S. (2014). İngilizce öğretiminde tersine eğitim uygulamasının değerlendirilmesi (Yayınlanmamış yüksek tisans tezi). Afyon Kocatepe Üniversitesi, Afyonkarahisar.

Bozkurt Altan, E. (2017). Disipliner yapıdaki derslerde STEM eğitimi: Tasarım temelli öğrenme ve probleme dayalı STEM uygulamaları. Fen, teknoloji, mühendislik ve matematik (FeTeMM-STEM) eğitimi. Salih Çepni (Ed). Ankara: Pegem Akademi Yayınları.

Büyüköztürk, Ş., Çakmak, E. K., Akgün, Ö. E., Karadeniz, Ş. ve Demirel, F. (2016). Bilimsel araştırma yöntemleri. Ankara: Pegem Akademi.

Carwile, J. (2007). A constructivist approach to online teaching and learning. Inquiry, 12(1), 68-73.

Choi, H. J. ve Johnson, S. D. (2005). The effect of context-based video instruction on learning and motivation in on-line courses. The American Journal of Distance Education, 19(4), 215-227.

Çalışkan, H. ve Turan, R. (2008). Araştırmaya dayalı öğrenme yaklaşımının sosyal bilgiler dersinde akademik başarıya ve kalıcılık düzeyine etkisi. Türk Eğitim Bilimleri Dergisi, 6(4), 603-627.

Çelik, E., Yıldırım, S. ve Yıldırım, G. (2018). Uygulayıcıların ters yüz edilmiş sınıf uygulamalarına yönelik deneyimleri. Ĕgitim Teknolojisi Kuram ve Uygulama, 8(2), 192-211.

Çiftçi, C. ve Çağlar, A. (2014). Ailelerin sosyo-ekonomik özelliklerinin öğrenci başarısı üzerindeki etkisi: Fakirlik kader midir? International Journal of Human Sciences, 11(2), 155-175.

Demiralay, R. ve Karataş, S. (2014). Evde ders okulda ödev modeli. Eğitim ve Öğretim Araştırmaları Dergisi, 3(3), 333-340.

Davis, S. A. (2005). Inquiry-based learning templates for creating online educational paths (Yayımlanmamıs yüksek lisans tezi). A\&M University, Texas.

Davis, B. C. ve Shade, D. D. (1994). Integrate, don't isolate computers in the early childhood curriculum [ERIC Document Reproduction Service]. Erişim adresi: https://files.eric.ed.gov/fulltext/ED376991.pdf

Duerdan, D. (2013). Disadvantages of a flipped classroom [Blog yazısı]. Erişim adresi: http://www.360edu.com/commentary/disadvantages-of-a-flipped classroom.htm\#.UtaQkvRdUpW.

Durak, Y. H. (2017). Ortaokul öğrencileri için ters yüz öğrenme hazırbulunuşluk ölçeğinin Türkçe'ye 
uyarlanması. Bartın Üniversitesi Ĕ̆itim Fakültesi Dergisi, 6(3), 1056-1068.

Engin, M. (2014). Extending the flipped classroom model: Developing second language writing skills through student-created digital videos. Journal of the Scholarship of Teaching and Learning, 14(5), 12-26.

Engin, M. ve Donanc1, S. (2014). Flipping the classroom in an academic writing course. Journal of Teaching and Learning with Technology, 3 (1), 94-98.

Farah, M. (2014). The impact of using flipped classroom instruction on the writing performance of twelfth grade female Emirati students in the applied technology high school (ATHS) (Yayımlanmamıs yüksek lisans tezi). The British University, Dubai.

Fer, S. ve Cırık, İ. (2006, Eylül). Yapılandırmacı öğrenme ortamı ölçeğinin geçerlik ve güvenirlik çalı̧ması. XV. Ulusal Eğitim Bilimleri Kongresinde sunulan bildiri, Muğla Sıtkı Koçman Üniversitesi Eğitim Fakültesi, Muğla.

Gençer, B., G., Gürbulak, N. ve Adıgüzel, T. (2014, Şubat). Ĕ̆itimde yeni bir süreç: Ters-yüz sınıf sistemi. International Teacher Education Conference Konferasında sunulan bildiri, Dubai, UAE .

Gençer, B. G. (2015). Okullarda ters-yüz sınıf modelinin uygulanmasına yönelik bir vaka çalışması. (Yayımlanmamış yüksek lisans tezi). Bahçeşehir Üniversitesi, İstanbul.

Hayırsever, F. ve Orhan, A. (2018). Ters yüz edilmiş öğrenme modelinin kuramsal analizi. Mersin Üniversitesi Ĕ̆itim Fakültesi Dergisi, 14(2), 572-596.

Iofciu, F., Miron, C. ve Antohe, S. (2011). A constructivist approach of advanced physics concepts: Using a cognitive map for the study of magnetoresistive materials. Procedia Social and Behavioural Sciences, 15, 461-465.

Johnson, D. (2012). Power up! Taking charge of online learning. Educational Leadership, 70(3), 84-85.

Karamustafaoğlu, S. ve Havuz, A. (2016). Inquiry based learning and its effectiveness. International Journal of Assessment Tools in Education, 3(1), 40-54.

Karasar, N. (2015). Bilimsel araştırma yöntemi. Ankara: Nobel Yayıncılık.

Kardaş, F. ve Yeşilyaprak, B. (2015). Eğitim ve öğretimde güncel bir yaklaşım: Teknoloji destekli esnek öğrenme (flipped learning) modeli. Ankara Üniversitesi Ĕ̆itim Bilimleri Fakültesi Dergisi, 48(2), 103-121.

Kertil, M. (2008). Matematik öğretmen adaylarının problem çözme becerilerinin modelleme sürecinde incelenmesi (Yüksek lisans tezi). Marmara Üniversitesi, İstanbul.

Korkmaz, Ö., Ozan, C. E. ve Karamustafaoğlu, S. (2016). Ortaokul öğrencilerinin araştırma sorgulamaya dönük öz-yeterlilik algi ölçeği. Türkiye Sosyal Araştırmalar Dergisi, 20(3), 679-695.

Kozikoğlu, İ. (2019). Analysis of the studies concerning flipped learning model: A comparative metasynthesis study. International Journal of Instruction, 12(1), 851-868.

Kurt, A. A., Çoklar, A. N., Kılıçer, K. ve Yıldırım,Y. (2008). Evaluation of the skills of K12 students regarding the national educational technology standards for students (Nets-S) in Turkey. The Turkish Online Journal Of Educational Technology, 7(3), 6-14.

Lage, M., Platt, G. ve Treglia, M. (2000). Inverting the classroom: A gateway to creating an inclusive learning environment. Journal of Economic Education, 31(1), 30-43.

McLaughlin, J. E., Roth, M. T., Glatt, D. M., Gharkholonarehe, N., Davidson, C. A., Griffin, L. M., ... ve Mumper, R. J. (2014). The flipped classroom: a course redesign to foster learning and engagement in a health professions school. Academic Medicine, 89(2), 236-243.

Neo, M. ve Neo, T. K. (2009). Engaging students in multimedia-mediated Constructivist learning-Students' perceptions. Journal of Educational Technology \& Society, 12(2), 254-266. 
Nikitina, L. (2010). Addressing pedagogical dilemmas in a constructivist language learning experience. Journal of the Scholarship of Teaching and Learning, 10(2), 90-106.

Odabaşı, H. F. (2010). Bilgi ve iletişim teknolojileri ışığında dönüşümler, H.F.Odabaşı (Ed.). Ankara: Nobel Akademik Yayıncilık.

Perry, V. R. ve Richardson, C. P. (2001, Ekim). The New Mexico tech Master of Science Teaching program: An exemplary model of inquiry-based learning. 31st Annual Frontiers in Education Conference Konferansinda sunulan bildiri, Reno, Nevada.

Rovai, A.P. (2004). A constructivist approach to online college learning. Internet and Higher Education, 7(2), 79-93.

Sever, G. (2014). Bireysel çalg1 keman derslerinde çevrilmiş öğrenme modelinin uygulanması. Journal of Qualitative Research in Education, 2(2), 27-42.

Talbert, R. (2012). Inverted classroom. Colleagues, 9(1), 18-19.

Tansel, A. (2002). Determinants of school attainment of boys and girls in Turkey: individual, household and community factors. Economics of Education Review, 21(5), 455-470.

Teachman, J. (1987). Family background, educational resources, and educational attainment. American Sociological Review, 52(4), 548-557.

Torun, F. ve Dargut, T. (2015). Mobil öğrenme ortamlarında ters yüz sınıf modelinin gerçekleştirilebilirliği üzerine bir öneri. Adnan Menderes Üniversitesi Ĕ̆itim Fakültesi Ĕ̆itim Bilimleri Dergisi, 6(2), 20-29.

Turan, Z. (2015). Ters yüz sını yönteminin değerlendirilmesi ve akademik başarı, bilişsel yük ve motivasyona etkisinin incelenmesi (Yayımlanmamış doktora tezi). Atatürk Üniversitesi, Erzurum.

Yaşar, Ş. ve Duban, N. (2009). Sorgulamaya dayalı öğrenme yaklaşımına yönelik öğrenci görüşleri. İlköğretim Online, 8(2), 457-475.

Yurdakul, B. (2010). Yapılandırmacılık. Ö. Demirel (Ed.), Eğitimde yeni yönelimler (s. 39- 65). Ankara: Pegem Akademi.

Zownorega, J. S. (2013). Effectiveness of flipping the classroom in a honors level, mechanics based physics class (Yayımlanmamış yüksek lisans tezi). Eastern Illinois University, Illinois. 


\section{EXTENDED ABSTRACT}

\section{Introduction}

With the rapid development of science and technology, change and development in social structure has become inevitable. These changes and developments had to show itself in the field of education. In today's age, formal or face-to-face learning is not sufficient alone to meet the educational needs of individuals and this situation brings learning out of the school environment. Therefore, educators are also looking for new technologies by using educational technologies. In this study, it is aimed to investigate the relationship between secondary school students' flipped learning readiness and their attitudes towards researching/questioning. Correlational survey model was used in this study. For this general purpose, the following questions were addressed in this study:

1. What are the level of secondary school students' attitudes towards researching/questioning and their flipped learning readiness?

2. Do secondary school students' attitudes towards researching/questioning and their flipped learning readiness differ significantly according to the variables such as having internet, computer, smart phone, socio-economic level of the school and family income level?

3. Is there a significant relationship between secondary school students' flipped learning readiness and their attitudes towards researching/questioning?

In contemporary education approach, new student-centered and technology-supported approaches emerge. These approaches prioritize the student's active participation in the learning process and the integration of technology into education. The student tries to reach the information by taking responsibility for learning and researching/questioning. There are studies in the literature concerning flipped learning (Bergmann, Overmyer and Wilie, 2012; Bergman and Sams, 2012; Boyraz, 2014; Çelik, Yıldırım and Yıldırım, 2018; Duerdan, 2013; Engin, 2014; Engin and Donanc1, 2014; Fer and Cırık, 2006; Gençer, 2015; Gençer, Gürbulak and Adıgüzel, 2014; Kozikoğlu, 2019; Turan, 2015) and attitude towards researching/questioning (Babadoğan and Gürkan, 2002; Çalışkan and Turan, 2008; Karamustafaoğlu and Havuz, 2016; Yaşar and Duban, 2009). However, no study has been reached on the relationship between secondary school students' flipped learning readiness and their attitudes towards researching/questioning. In this respect, this study is important in terms of determining the relationship between secondary school students' attitudes towards researching/questioning and flipped learning readiness. In addition, most of the studies in the literature on flipped learning are experimental studies examining the effect of flipped learning on various variables. However, factors such as materials, opportunities, students and teachers must be suitable for flipped learning to be applied effectively. Therefore, it is thought that this study will contribute to the literature in order to determine flipped learning readiness of the students as one of these factors. In addition, this study is important in determining secondary school students' attitudes towards researching/questioning, which is one of the 21st century learning skills.

\section{Method}

This study was conducted with 362 secondary school students studying in Van. As data collection tools, "Flipped Learning Readiness Scale for Secondary School Students and "Attitude towards Researching/Questioning Scale for Secondary School Students" were used. Arithmetic mean, standard deviation, $\mathrm{t}$ test, ANOVA and Pearson Product Moment Correlation Coefficient were used for data analysis.

\section{Results}

As a result of the study, it was determined that secondary school students' attitudes towards researching/questioning and their flipped learning readiness are at high level. In this study, it was concluded that students with internet connection at home had higher level of flipped learning readiness and attitudes towards researching/questioning. It was concluded that students with computer and smart phone had higher level of flipped learning readiness, but students' attitudes towards researching/questioning did not show significant difference according to having computer and smart phone. It was determined that the students, 
who study at schools with high socio-economic development level, have higher level of flipped learning readiness and attitudes towards researching/questioning. It was determined that students with a high level of family income had higher flipped learning readiness; however, it was determined that students' attitudes towards researching/questioning did not show significant difference according to family income level. In addition, it was concluded that there is a positive and significant relationship between secondary school students' attitudes towards researching/questioning and their flipped learning readiness.

\section{Conclusion}

As a result, it was observed that the students' attitudes towards researching/questioning and their flipped learning readiness differed significantly according to the variables such as internet, technological tools, family income level and socio-economic development level of the school. In line with the results of this study, it should be ensured that students intertwined with computer and internet as much as possible, considering that the possibility of continuous use of information technologies improves flipped learning readiness. For flipped learning, course contents can be transferred to a DVD for students who do not have the necessary internet access. At the same time, students with low technology competence should be encouraged to use the internet and technology. Considering the importance of differentiating instruction with research-oriented approach and flipped learning model, it is thought to be important in increasing the teachers' motivation to use and inform about these approaches and technologies. 